\title{
Developing Business Architecture for SMEs: A Strategic Tool for Capability Orchestration and Managing Dynamisms
}

\author{
Seyran Gh. Dehbokry and Eng K. Chew \\ University Technology, Sydney, Australia \\ Correspondence should be addressed to: Seyran Gh. Dehbokry; \\ seyran.ghahramanydehbokry@student.uts.edu.au
}

Received date: 9 September 2013; Accepted date: 18 June 2014; Published date: 27 May 2015

Copyright @ 2015 Seyran Gh. Dehbokry and Eng K. Chew. Distributed under Creative Commons CCBY 4.0

\begin{abstract}
Small and Medium Enterprises (SMEs) are increasingly faced with competitive pressure due to swift and constant change to the dynamic and highly interconnected environment in which they operate. Competing in this dynamic ecosystem, SMEs need a strategic tool for managing coevolution with the dynamic environment in order to create sustained value. Drawing from the specific SME characteristics operating in a collaborative network ecosystem of firms, this paper elicits the specific strategic management requirements that need to be satisfied by a Business Architecture. Extensive exploratory literature review and semi-structured interviews are used to explicate the underlying drivers of SME's requirements for business architecture that need to be addressed by the requisite BA practice. The paper finds that, the BA practice must possess the capabilities to guide and assist the SMEs to adapt with the dynamic collaborative ecosystem of firms and sense, leverage and orchestrate the network of resources and ICT capabilities to create sustained value. This paper concludes with some guidelines for developing the business architecture-enabled journey toward creating sustained value within the said dynamic ecosystem.
\end{abstract}

Keywords: Business Architecture (BA), Small and Medium Enterprises (SMEs)

\section{Introduction}

Small and Medium Enterprises (SMEs) are a key driver of a nation's economic growth (Ayyagari et al., 2007). Competing in a dynamic collaborative global ecosystem, SMEs need a strategic management tool to help develop the requisite capabilities, structure, and integrate and leverage the underlying resources in line with the dynamic market and ecosystem conditions. More importantly the emphasis has been on investment, management and promotion of ICT and its related resources and capabilities through adaptation of a variety of IT management solutions which in many cases have not realized the value originally expected (Karvonen, 2011).

In this context Business Architecture (BA) may seem to be ideal solution as a strategic management tool to help manage and structure business, to leverage ICT capability, information and knowledge and to facilitate the IT decision making process, alignment to the business goal and manage dynamic environments (Mingxin and Lily, 2009, Choi et al., 2008).So far an initial

Cite this Article as: Seyran Gh. Dehbokry and Eng K. Chew (2015), "Developing Business Architecture for SMEs: A Strategic Tool for Capability Orchestration and Managing Dynamisms," Journal of Innovation Management in Small and Medium Enterprise, Vol. 2015 (2015), Article ID 774202, 
research has defined applicable architecture frameworks for SMEs which, however, is mostly focused on IT (but not business) architecture (Jacobs et al., 2011). However, to our best knowledge, currently there has been no BA framework defined for SMEs yet. Simultaneously the implementation and the use of current enterprise architecture practices is a daunting task for SMEs and requires a substantial investment in organizational resources in terms of time, people, and financial (Harishankar and Daley, 2011).

The main goal for this paper is to explore what are the major SMEs requirements that the BA practice should address. Accelerating technological changes, rapidly changing market demands and growing globalized collaborative networked organizations (Zeng et al., 2010), coupled with the SME's inherent limitations and resource constraints (Antlova, 2010), underscore the need for applying businessoriented architecture as strategic management tool for SMEs to create sustained value. Likewise in this paper we focus on how BA enables SMEs first to manage and orchestrate their limited resources and capabilities, mainly ICTs, and second to create sustained value within dynamic collaborative ecosystems. Thus based on extant literature review and interviews conducted with SMEs managers and industry experts we aim answer following questions:

- RQ1: What are the BA practice attributes that make it applicable to SMEs?

- RQ2: How does BA enable SMEs to deal with their resource limitations and constraints?

- RQ3: How does BA enable SMEs to create sustained value in a dynamic collaborative ecosystem?

Thus this paper is structured as follows. First, we review the organizational and environmental characteristics of SMEs that encourage them to use BA as a strategic management tool. Second, the strategic organizational purpose of BA is explained to set the context for exploring the SME requirements for $\mathrm{BA}$. Third we describe our research approach and present the finding of our study in three parts to answer the above research questions. Finally, we conclude the paper with a summary of the guidelines and insights for SMEs to develop a BA framework.

\section{SMEs and Strategic Requirements for BA Practice}

SMEs have a vital role in nation's economic growth, innovation and employment (Commission, 2010). Due their significance, studies of their business advancement and development which lead to possible economic and social development, have gained increased attention for most scholars and practitioners (Commission, 2010). More specifically the focus has been given to ICT usage and utilizations as an essential ingredient of business resources and capabilities in order to create better value within dynamic environments (Antlova, 2010). The key factors that encourage SMEs to develop and use a strategic management tool such as BA can be categorized in terms of internal organizational and external environmental factors.

Although the advantage of ICT adaption within SMEs is clearly illustrated (Wang and Shi, 2011, MacGregor and Vrazalic, 2005), one should be aware of the importance of strategic management, resource and capability orchestration and associated ICT investment decision making process in order to create sustained value from such resources and capabilities (Levy et al., 2001). Although enterprise systems and processes have been structured in SME's value chain using ERP, CRM and BPM (Bajwa et al., 2009, Feldbacher et al., 2011, Ignatiadis et al., 2010), a wide range of extant SME research has shown substantial problems for SMEs to define and govern the implementation of IT strategy to realize technology change in alignment with their business (Vos, 2005, Catteddu and Hogben, 2009). Indeed the need for a BA has been called for in order to articulate the structure of business processes, governance, information systems strategies 
and to align IT solution to business strategies and requirements(Burton, 2008). Developing strategies and clear roadmap around ICT capabilities for SMEs, will more likely enable them to identify new technologies, improve performance of new systems along with utilizing and better leveraging current capabilities (Riemenschneider and Mykytyn, 2000).

SMEs as a main participant of collaborative networks (Camarinha-Matos, 2009) are engaged in information exchange, resource acquisition and technology transformation which help them to overcome the lack of resources and challenges that they are facing in the dynamic ecosystems (Nieto and Santamaría, 2010). The openness of such dynamic ecosystems drives SMEs to develop the capabilities and capacities in order to; (a) be susceptible to sense and acquire opportunities from external innovations, (b) adapt to the new network structure whether it is technology, systems or business structure. SMEs have developed ICT solutions and structures to meet dynamic market demands and adapt to different ecosystems (Ignatiadis et al., 2010). However, not only will the internal organization interoperability, infrastructure, technology, information, strategy and business structure determine the operation and formation of collaboration networks, but also appropriate architecture principle, ICT strategies and technology alignment are required to enhance network goal (Fjeldstad et al., 2012).

\section{The Role of Business Architecture}

Business Architecture (BA) is a multidisciplinary concept which represents the real-world aspect of the business and integrates the fundamental disparate concepts of an organization to guide its transformation to the target or new organizations $^{1}$ (al, 2009). Using BA concept enables organizations to describe current and future states, the relationship between its internal and environmental elements, defines the strategies and the associated roadmap to articulate these strategies in measurable and actionable ways (Burton, 2008). Using this capability enable ICTs to create more value for organisation internally as well as within collaborative ecosystems (Bradley et al., 2011). BA is an ongoing process to manage internal and external changes and to re-engineer organizational structure in terms of business processes, knowledge, strategy and business capabilities to adapt to the new environment (Hoogervorst, 2004).

BA practices have been applied to large enterprises and the use of this approach has become a top priority for many of their managers (Bradley et al., 2011). Various BA approaches have been presented, differing in purpose, level of details and scops. They have been categorised as either "businesscentric" or "IT-centric", focusing respectively on business or ICT aspect within the organisation (Glissmann and Sanz, 2010). The requirements which the BA practice needs to fulfill depend upon the enterprise characteristics and objectives in their business transformation. The value of BA is likewise expected to be significant for small and medium enterprises. But due to the resource-constraints and nature of SMEs with their idiosyncratic characteristics and requirements, further investigations are required to explicate the specific BA attributes applicable to SMEs.

\section{Research Methodology}

In order to address our research questions, we conducted semi-structured interviews with three SMEs and three industry experts from multinational IT consulting companies as well as extensive exploratory literature review. The respondents included SME managers/owners which represented public sector as well as Business Architecture specialists (from consulting firms). The selected SMEs are drawn from different sectors, since they are facing challenges in transforming, managing and orchestrating computing technologies and related capabilities as well as adapting to the dynamics of networked organizations.

The interview results are supported by the literature review and presented in three categories to answer the research questions. First, the general BA practice 
attributes are derived from the SMEs strategic management requirements and their related specific structure. Resource constraints and the importance of resources and capabilities within their organization drive the second category. Since collaborative organization network evolves, the new requirements have called for distinct capabilities in terms of structure, process and knowledge and ICT. In line with SME requirements within a collaborative ecosystem, the third category covers the adaptability challenges that the requisite BA needs to address.

\section{General BA Practice Attributes Applicable to SMEs}

Developing architectures in different levels of an enterprise can be a daunting task for any business, but more challenging for small and medium sized enterprises (Bidan et al., 2012). The challenges faced by SMEs are related to their specific characteristics, constraints and resource shortages. The limited number of trained and experienced people within their organization causes the small team of managers to be responsible for many tasks and perform a central role in their decision making process. In essence, resource shortages drive SMEs to seek for a simple, quick-action strategic management practice for managing the entire strategic ICTs planning and implementation lifecycle that can be readily and easily applied by small group of people (mainly SME managers and owners)(Gagalis et al., 2010, Sternad et al., 2010). Both SMEs manager and consultant interviewees have acknowledged this. An Enterprise Architect stated it this way: "...I would suggest a framework that is easy to initialize in a relatively green-field situation. Being a more intuitive and understandable framework for small business owners and managers, encourage the use of developed roadmap in the decision making process. " A small government agency's manager indicated their needs in this way: “... we need a roadmap that is not relying on complicated techniques and elaborate framework." A small university agency required " $A$ solutions that can be trained to the group of our manager and be managed in their later stages". Therefore the "simplicity" and "easy to learn" properties or features of the BA become a valid concern for both SMEs and industry experts. The simplicity of BA practice was addressed by an Enterprise Architect in this statement; "Based on a business context and the elements pertinent to that context would constitute "simplified" BA that is meaningful to the SMEs executives" As each SME may be at a very different start point on their business architecture journey and facing different challenges, "...the framework's attributes may need to be tailored and adjusted for each of them", a Business Architect suggested. This would contribute the adaptability of the framework.

\section{ICT Capability Management and Orchestration}

Due to SMEs' specific business characteristics in terms of working capital constraints and lack of resources, they have a pressing need to strategically structure and manage their ICTs capabilities and resources in line with the changing external environments. Besides that, SMEs are facing pressure in making decisions around three types of issues. First, selecting the fit-for-purpose ICT capabilities in line with the resource constraints requirements (Blackwell et al., 2006). Second, as a consequence of the first, making strategic decisions as to where to make the appropriate ICT investment (Levy et al., 1999). The third is how to utilize and integrate the new system or technology into the business in order to enhance the business (growth) performance and/or reduce the total operational costs (Jacobs et al., 2011). These underscore the importance of BA as a strategic tool that facilitates the decision making process and enables SMEs to orchestrate, integrate, manage and structure their business resources and ICT capabilities in line with external environmental dynamics.

This is aptly demonstrated by the strategic challenge faced by the owner of a private college (SME) who was concerned with integrating the current system with potential new systems; "We have developed 
three systems independently and now we are facing challenges in linking them together" was his introductory remarks. "Our main problem is now we need to develop more systems to be able to run our courses online across the country". A second problem is "we need to use current systems and their capabilities as we have spent resources on them and cannot get rid of them, Our systems and IT capabilities should have been developed to embrace the new requirements", he indicated. A third problem is "we are surrounded by different solutions and cannot make decision which one is the best suitable system to fulfil future needs and comply with current systems" he added.

Looking further to the SME's ICT requirements, the increasingly popular and disruptive cloud computing technologies have captured the SMEs' attention. This is because of cloud computing technology's ability for provisioning capabilities and resources (known as services - such as "software as a service") with lower cost and immediate accessibility (Marston et al., 2011). This "software as a service" model creates a new horizon of opportunities for SMEs where provides an efficient way for them to leverage shared ICT capabilities and services. Despite the advances in cloud computing, there are significant structural, organizational issues that SMEs need to tackle with before they can move to this environment (Sultan, 2011). Moving toward cloud computing requires SMEs to consider (analyze/select) and plan for proper architecture in term of business and technology to leverage the advantages or opportunities provided by the new technology (Bohra and Rathore, 2012). This is acknowledged by a general manager at Midmarket IBM in his recent blog post; ... "the journey to the cloud becomes inevitable and the question shifts from whether to adopt cloud technologies to how to do so sensibly ${ }^{1 "}$. Another industry expert also acknowledged the significance of BA and mentioned; ... "I believe that Business Architecture is our best tool to facilitate migration towards cloud in companies.... Its use in these disruptive scenarios is one of the reasons why business architecture has value even when it isn't integrated with those other layers".

However, the group of enterprises and industry experts agreed that the integration, orchestration, management and evolution of SME's ICTs resources and competencies are an important issue. Thus, according to the college owner's perspective of their current- and futurestate strategic requirements, the new BA practice should guide the evolution, integration and orchestration of business competencies specifically and the corresponding ICT resources to address new (future-state) business requirements. Furthermore the proposed BA practice should support sensing the unseen opportunities and guide SME's business investments to where they can create the most sustained value.

\section{Adapting to the Dynamic Collaborative Environments and Managing Dynamism}

The main SME's need for BA as strategic tool has been driven by dynamic environment challenges. Collaborating with the network of organizations and adapting to the ecosystems, the dynamic market demands and technological changes are the key factors that need to be addressed by the requisite $\mathrm{BA}$. In a dynamic collaborative ecosystem, SMEs need to think strategically in all aspects of their business and structure, bundle and leverage network and firm resources and capabilities with the purpose of creating value (Nieto and Santamaría, 2010). Participating in a collaborative network, facilitated by globalized ICTs, SMEs are increasingly confronted with three issues. The first issue is defining aligned business and ICTs strategies that are congruent with the market, network and technological changes. The second issue is concerned with managing network adaptability through inter-firm interoperability from both technological and business level perspectives (Westphal et al., 2010). The third issue is concerned with achieving market penetration and creating value through meta-capabilities that can synchronize and integrate inter-firm networked competencies and resources to 
co-create value. These considerations underscore the development of the requisite BA practice (or capabilities) that enables SMEs to manage a variety of networked organizations and simultaneously to create sustained value by leveraging the environmental opportunities (Allred et al., 2011). The new $\mathrm{BA}$ practice requirement is reflected in this statement by an Enterprise Architect and consultant, "In the new way of business where SMEs must dynamically evolve in a continuously changing environment, the $B A$ framework should extend its focus beyond organizational boundaries to the business network ecosystem".

For the majority of SMEs we interviewed, participating within networked organisations is a critical requirement in order to fully utilize and leverage their networked resources to continuously cocreate new product and services. A small sized government agency (public service) requires collaborating with different industry bodies and state and territory governments. "We require ongoing investments in intangible assets, such as ability to collaborate and integrate with our stakeholders", the agency's CEO indicates. "Our systems and business structures are defined by experiences and based on new projects as well as the government policies. The resources that each company within the network has assembled are often shared with other companies. We are independent member and it is each company's responsibility to build and maintain its capability to develop its resources and leverage the shared resources and capabilities", he added. An owner of a small sized college which is collaborating with the group of universities requires a clear roadmap to "integrate within the network" and at the same time "leverage assembled systems and other capabilities available for the members". Knowledge intensive organizations are heavily reliant on open innovation and value creation in collaborative networks, so their need for proper architecture is even more discernible to facilitate the value cocreation process (Fjeldstad et al., 2012).

Furthermore business and technological integration and alignment of the collaboration network, sense-making of the external market and new technological opportunities and threats, and leveraging these opportunities are all important requirements for the SME to survive and thrive as a main participant in the global collaboration network. These requirements must be addressed effectively by the BA practice. However "as each SME may be at a very different start point on their business architecture journey and facing different challenges and requirements, the Business Architecture practice may need to be adjusted and tailored," as indicated by an industry expert.

\section{Conclusions and Some Guidelines for Defining Applicable Business Architecture for SMEs}

Our literature review and empirical findings from the interviews with SME owners/managers and industry experts revealed that BA conceptually is highly desirable by SMEs as a strategic management tool for dealing with resources constraints and for managing coevolution with the dynamic market and technological environments to create sustained value. The interviews showed that the organizational capabilities for internal and external ICTs resources orchestration, integration and management in a collaborative network of firms are fundamental requirements that must be satisfied by the requisite $\mathrm{BA}$ practice. To that end the BA practice should strategically position SMEs within the collaborative network and enable them to leverage, manage and orchestrate internal and external resources and capabilities to create sustained value. Our research has yielded some guidelines on developing the requisite BA for SMEs, which are showed in table 1. 
Table 1: Guideline for Developing BA Practice for SMEs

\begin{tabular}{|c|c|c|}
\hline $\begin{array}{c}\text { Area of } \\
\text { Research }\end{array}$ & $\begin{array}{l}\text { Research } \\
\text { Questions }\end{array}$ & $\begin{array}{c}\text { Summary of Guidelines for BA Practice in } \\
\text { SMEs }\end{array}$ \\
\hline $\begin{array}{l}\text { BA practice } \\
\text { development } \\
\text { applicable to } \\
\text { SMEs }\end{array}$ & $\begin{array}{l}\text { What are the } \\
\text { BA practice } \\
\text { attributes } \\
\text { that make it } \\
\text { applicable to } \\
\text { SMEs? }\end{array}$ & $\begin{array}{l}\text { BA practice should be performed in short } \\
\text { period of time in close collaboration with SME's } \\
\text { management/executive team. } \\
\text { BA practice should be managed, governed and } \\
\text { evolved by SME's managers/executives. Hence } \\
\text { training and awareness should be included in } \\
\text { the practice. } \\
\text { Use simple business oriented pragmatic } \\
\text { architecture practice and avoid the complex } \\
\text { and technical based practice }\end{array}$ \\
\hline $\begin{array}{l}\text { Integrating and } \\
\text { orchestrating } \\
\text { socio-technical } \\
\text { resources/cap } \\
\text { abilities }\end{array}$ & $\begin{array}{l}\text { How does BA } \\
\text { enable SMEs } \\
\text { to deal with } \\
\text { their resource } \\
\text { limitations } \\
\text { and } \\
\text { constraints? }\end{array}$ & $\begin{array}{l}\text { Capability based architecture practice is } \\
\text { required to map and orchestrate socio-technical } \\
\text { resource/capabilities } \\
\text { Architecture practice should result in a } \\
\text { business-aligned configuration of resources to } \\
\text { attain evolutionary fitness with the competitive } \\
\text { environments. } \\
\text { BA practice should facilitate ICT decision } \\
\text { making process by defining contingent } \\
\text { strategies with dynamic ecosystem. }\end{array}$ \\
\hline $\begin{array}{l}\text { Managing co- } \\
\text { evolution } \\
\text { within } \\
\text { ecosystems }\end{array}$ & $\begin{array}{l}\text { How does BA } \\
\text { enable SMEs } \\
\text { to create } \\
\text { sustained } \\
\text { value in a } \\
\text { dynamic } \\
\text { collaborative } \\
\text { ecosystem? }\end{array}$ & $\begin{array}{l}\text { BA practice for SMEs should drive the value } \\
\text { proposition in the chosen ecosystem. } \\
\text { BA practice should enable SMEs to develop and } \\
\text { execute business strategies that fulfil the value } \\
\text { proposition in alignment with the dynamic } \\
\text { ecosystem. } \\
\text { Build the capabilities to sense, seize and } \\
\text { integrate ecosystem opportunities and threats. }\end{array}$ \\
\hline
\end{tabular}

\section{Notes}

1 TOGAF Version 9

${ }^{2}$ http://www.linkedin.com/today/post/article/20140 425201913-133994-smbs-journey-to-the-cloud

\section{References}

1.Al, A. J. E. (2009). TOGAF Version 9,' United Kingdom, The Open Group.

2.Allred, C. R., Fawcett, S. E., Wallin, C. \& Magnan, G. M. (2011). "A Dynamic Collaboration Capability as A Source of Competitive Advantage," Decision sciences, $42,129-161$.

3.Antlova, K. (2010). "Preparedness of Small and Medium-Sized Enterprises to Use Information and Communication Technology as a Strategic Tool," Enterprise
Information Systems for Business Integration in SMEs: Technological, Organizational, and Social Dimensions, 342.

4.Ayyagari, M., Beck, T. \& Demirguc-Kunt, A. (2007). "Small and Medium Enterprises across the Globe," Small Business Economics, 29, 415-434.

5.Bajwa, I. S., Samad, A., Mumtaz, S., Kazmi, R. \& Choudhary, A. (2009). "BPM Meeting with SOA: A Customized Solution for Small Business Enterprises," 2009. IEEE, 677682.

6.Bidan, M., Rowe, F. \& Truex, D. (2012). "An Empirical Study of IS Architectures in French SMEs: Integration Approaches†," European Journal of Information Systems, 21, 287-302. 
7.Blackwell, P., Shehab, E. M. \& Kay, J. M. (2006). "An Effective Decision-Support Framework for Implementing Enterprise Information Systems within SMEs," International Journal of Production Research, 44, 3533-3552.

8.Bohra, R. \& Rathore, V. S. (2012). 'Collaboration between SOA and Cloud Computing at a Glance,' International Journal of Recent Technology and Engineering, 1, 88.

9.Bradley, R., Pratt, R., Byrd, T. A. \& Simmons, L. (2011). "The Role of Enterprise Architecture in the Quest for it Value," MIS Quarterly Executive, 10, 19-27.

10.Burton, B. (2008). 'Understand Enterprise Business Architecture to Realize Your Future State,' Gartner.

11.Camarinha-Matos, L. M. (2009). "Collaborative Networked Organizations: Status and Trends in Manufacturing," Annual Reviews in Control, 33, 199-208.

12.Catteddu, D. \& Hogben, G. (2009). "An SME Perspective on Cloud ComputingSurvey,' Technical Report, European Network and Information Security Agency.

13.Choi, Y., Kang, D., Chae, H. \& Kim, K. (2008). "An Enterprise Architecture Framework for Collaboration of Virtual Enterprise Chains," The International Journal of Advanced Manufacturing Technology, 35, 1065-1078.

14.Commission, E. (2010). 'European SMEs under Pressure: Annual Report on EU Small and Medium-Sized Enterprises 2009,' European Commission, Directorate-General for Enterprise and Industry, Report prepared by EIM Business \& Policy Research.

15.Feldbacher, P., Suppan, P., Schweiger, C. \& Singer, R. (2011). "Business Process Management: A Survey among Small and Medium Sized Enterprises," S-BPM ONELearning by Doing-Doing by Learning, 296312.

16.Fjeldstad, Ø. D., Snow, C. C., Miles, R. E. \& Lettl, C. (2012). "The Architecture of
Collaboration," Strategic Management Journal, 33, 734-750.

17.Gagalis, D., Tahinakis, P., Protogeros, N. \& Ginoglou, D. (2010). "Challenges and Trends towards an Effective Application of ERP and SCM Systems in SMEs," Enterprise Information Systems for Business Integration in SMEs: Technological, Organizational, and Social Dimensions, 376.

18.Glissmann, S. \& Sanz, J. (2010). "Business Architectures for the Design of Enterprise Service Systems," Handbook of Service Science, 251-282.

19.Harishankar, R. \& Daley, S. K. (2011). "Actionable Business Architecture. Commerce and Enterprise Computing (CEC)," 2011 IEEE 13th Conference on, 2011. IEEE, 318-324.

20.Hoogervorst, J. (2004). "Enterprise Architecture: Enabling Integration, Agility and Change," International Journal of Cooperative Information Systems, 13, 213233.

21.Ignatiadis, I., Katriou, S. A., Koumpis, A. \& Tektonidis, D. (2010). "PANDA: A Virtual Breeding Environment for SMEs in the ERP/CRM Industry Using a Service Oriented Approach," World Review of Science, Technology and Sustainable Development, 7, 51-66.

22.Jacobs, D., Kotzé, P., van der Merwe, A. \& Gerber, A. ( 2011). "Enterprise Architecture for Small and Medium Enterprise Growth," Advances in Enterprise Engineering V, 6175.

23.Karvonen, I. (2011). "Towards Achieving Benefits of IT Utilization in Collaboration Networks," Adaptation and Value Creating Collaborative Networks, 517526.

24.Levy, M., Powell, P. \& Galliers, R. (1999). "Assessing Information Systems Strategy Development Frameworks in SMEs," Information \& Management, 36, 247-261. 25.Levy, M., Powell, P. \& Yetton, P. (2001). "SMEs: Aligning IS and the Strategic 
Context," Journal of Information Technology, 16, 133-144.

26.Macgregor, R. C. \& Vrazalic, L. (2005). “A Basic Model of Electronic Commerce Adoption Barriers: A Study of Regional Small Businesses in Sweden and Australia," Journal of Small Business and Enterprise Development, 12, 510-527.

27.Marston, S., Li, Z., Bandyopadhyay, S., Zhang, J. \& Ghalsasi, A. (2011). "Cloud computing-The Business Perspective," Decision support systems, 51, 176-189.

28.Mingxin, G. \& Lily, S. (2009). "Dynamic Convergence of Business and IT Systems through Enterprise Isomorphic Architecture," Information Technology and Computer Science, 2009. ITCS 2009. International Conference on, 2009. IEEE, 366-369.

29.Nieto, M. J. \& Santamaría, L. (2010). "Technological Collaboration: Bridging the Innovation Gap between Small and Large Firms*," Journal of Small Business Management, 48, 44-69.

30.Riemenschneider, C. K. \& Mykytyn, P. P. (2000). "What Small Business Executives Have Learned about Managing Information Technology," Information \& Management, 37, 257-269.
31.Sternad, S., Bobek, S., Dezelak, Z. \& Lampret, A. (2010). "Critical Success Factors (CSFs) for Enterprise Resource Planning (ERP) Solution Implementation in SMEs: What Does Matter for Business Integration," Enterprise Information Systems for Business Integration in SMEs: Technological, Organizational, and Social Dimensions. IGI Global.

32.Sultan, N. A. (2011). "Reaching for the "Cloud": How SMEs Can Manage," International journal of information management, 31, 272-278.

33.Vos, J. P. (2005). "Developing Strategic Self-Descriptions of SMEs," Technovation, 25, 989-999.

34.Wang, Y. \& Shi, X. (2011). "Thrive, Not Just Survive: Enhance Dynamic Capabilities of SMEs through IS Competence," Journal of Systems and Information Technology, 13, 200-222.

35.Westphal, I., Thoben, K. D. \& Seifert, M. (2010). "Managing Collaboration Performance to Govern Virtual Organizations," Journal of Intelligent Manufacturing, 21, 311-320.

36.Zeng, S. X., Xie, X. M. \& Tam, C. M. (2010). "Relationship between Cooperation Networks and Innovation Performance of SMEs," Technovation, 30, 181-194. 